\title{
Prediction of melt depth in selected architectural materials during high power diode laser treatment
}

\author{
J. Lawrence ${ }^{+}$, A.A. Peligrad*, E. Zhou*, L. Li ${ }^{+}$and D. Morton* \\ * Faculty of Technology, Bolton Institute, Deane Road, Bolton, BL3 5AB, UK. \\ ${ }^{+}$Laser Processing Research Centre, Department of Mechanical Engineering, University of \\ Manchester Institute of Science and Technology (UMIST), Manchester, M60 1QD, UK.
}

\section{Correspondence}

Dr. Jonathan Lawrence

Manufacturing Division,

Department of Mechanical Engineering,

University of Manchester Institute of Science and Technology (UMIST),

Manchester,

M60-1QD,

UK.

Tel : (44) $161236-3311$

Fax : (44) 161 200-3803

e-mail : j.lawrence@umist.ac.uk 


\begin{abstract}
The development of an accurate analysis procedure for many laser applications, including the surface treatment of architectural materials, is extremely complicated due to the multitude of process parameters and materials characteristics involved. A one-dimensional analytical model based on Fourier's law, with quasi-stationary situations in an isotropic and inhomogeneous workpiece with a parabolic meltpool geometry being assumed, was successfully developed. This model, with the inclusion of an empirically determined correction factor, predicted high power diode laser (HPDL) induced melt depths in clay quarry tiles, ceramic tiles and ordinary Portland cement (OPC) that were in close agreement with those obtained experimentally. It was observed, however, that as the incident laser line energy increased $\left(>15 \mathrm{~W} \mathrm{~mm}^{-1} \mathrm{~s}^{-1 / 2}\right)$, the calculated and the experimental melt depths began to diverge at an increasing rate. It is believed that this observed increasing discrepancy can be attributed to the fact the model developed neglects sideways conduction which, although it can be reasonably neglected at low energy densities, becomes significant at higher energy densities since one-dimensional heat transfer no longer holds true.
\end{abstract}

Keywords: High power diode laser (HPDL); Ceramic; Ordinary Portland cement (OPC); Analytical model; Melt depth 


\section{Introduction}

The unique characteristics of lasers provides them with the capability for the non-contact processing of materials which are otherwise difficult to process, such as clay quarry tiles, ceramic tiles and ordinary Portland cement (OPC).

The laser processing of concrete is a relatively large field of ongoing research, with many studies having been carried out to investigate the technique itself and the associated phenomena. Most of the research, however, has concentrated on the laser cutting of concrete and reinforced concrete using high power $\mathrm{CO}_{2}$ lasers, most prominently with regard to nuclear reactor decommissioning [1-3]. Also, as part of nuclear plant decommissioning, Li et al. [4-7] conducted research to determine the workability of several laser techniques for sealing/fixing radioactive contamination onto concrete surfaces. Such techniques experimented with were: direct glazing of the concrete, single and multiple layer fusion cladding and combined chemical/fusion cladding. In addition, Johnston et al. [8] have reported on the successful removal of the surface layer of concrete (scabbling) by means of Nd:YAG and $\mathrm{CO}_{2}$ laser radiation. Work by Sugimoto et al. [9] focused upon modifying the surface appearance and surface properties of cement based materials using a high power $\mathrm{CO}_{2}$ laser. The laser treatment produced novel surfaces, with surface textures, properties and appearance unique to laser treatment. The resultant physical characteristics and mechanical behaviour of the post-process cement based materials was later fully characterised by Wignarajah et al. [10]. Borodina et al. [11] has carried out investigations into the structural changes within the composition of zirconia concrete caused by surface exposure to $\mathrm{CO}_{2}$ laser radiation, detailing microstructural changes, phase changes and the absorptivity characteristics. In all of these studies, spallation and excessive cracking and porosity formation were found to be major problems undermining the performance of the laser treated surface layer. However, Lawrence and $\mathrm{Li}$ [12-15] have treated the OPC surface of concrete with both $\mathrm{CO}_{2}$ and high power diode lasers (HPDL). The HPDL generated OPC glaze was shown to be more than an effective surface modification insofar as it provided superior mechanical, physical and chemical characteristics over an untreated or $\mathrm{CO}_{2}$ laser treated OPC surface.

In contrast to concrete, relatively very little research has been conducted to study the effects and develop laser-based techniques for the actual processing of commercially available ceramic tiles. Of the work that has been carried out, the most active field by far has been the cutting of ceramic tiles with $\mathrm{CO}_{2}$ lasers. Work by Livingstone et al. $[16,17]$ studied the effects of laser operating parameters 
and cut profiles on the resultant cut quality. The findings of these investigations were carried further by Black et al. [18] in order to develop a laser beam machining (LBM) database for the cutting of ceramic tiles. The cutting of thick section $(>8.5 \mathrm{~mm})$ ceramic tiles with a $\mathrm{CO}_{2}$ laser was studied by Black and Chua [19] to determine the optimum laser operating parameters to effect the highest cut quality. Additionally, a two-dimensional model to predict the theoretical temperature distribution within the thick section tiles during the laser cutting was developed by Chua and Black [20]. Notwithstanding these comprehensive investigations, a detailed ceramic tile laser cutting process examination carried out by Solomah [21] concluded that the technique was best suited to the 'roughing out' of complicated geometries because, although the process was far quicker and more versatile than conventional cutting methods, the resulting porosities would prove to be a significant problem. Much work, however, has been previously carried out to investigate the laser marking of a variety of other ceramic materials. Using both $\mathrm{CO}_{2}$ and Nd:YAG lasers, Markov et al. [22] investigated the feasibility of marking a number of ceramic products used in the electrical and electronics industries. Likewise, Kugler et al. [23] studied the practicability of employing $\mathrm{CO}_{2}$ and Nd:YAG lasers to mark actual ceramic components used in the electronics industry. The findings of both studies gave a good indication that the laser is a viable option in ceramics marking in terms of speed and accuracy. The predominant area of current laser ceramic processing research, however, is in the cutting of various types of ceramic materials. This has led to the development of cutting processing models for the cutting of aluminium oxide $\left(\mathrm{Al}_{2} \mathrm{O}_{3}\right)$ [24], silicon nitride $\left(\mathrm{Si}_{3} \mathrm{~N}_{4}\right)$ [25], silicon carbide ( $\mathrm{SiC})[26]$ and zirconium oxide $\left(\mathrm{ZrO}_{2}\right)$ [27] ceramics with $\mathrm{CO}_{2}$ and $\mathrm{Nd}: Y A G$ lasers. It has also led to research into the suitability of laser cutting certain ceramics, namely silicon nitride and cordierite ceramics, due to their resistance to thermal cracking [27, 28].

Owing to the multitude of process parameters involved, the development of an accurate analysis procedure for many laser applications, including the surface treatment of many engineering ceramic materials, is extremely complicated. Moreover, laser process parameters must be carefully selected in order to achieve satisfactory results. As such, the development of a suitable model to predict such changes cannot only eliminate the need to perform experiments with every possible range of operating parameters, but can also provide information outside the range of operating parameters currently possible. For many laser processes a large number of analytic models currently exist for the prediction of the thermal behaviour of materials during laser surface processing. These are mainly based on classic analytical solutions to temperature distribution derived by Jeager [29], Rosenthal 
[30], Carslaw and Jeager [31] and Patankar [32]. Using the Fourier integral transform method, Cheng and Kar [33] developed a three-dimensional quasi-steady state heat conduction model to study the densification of a laser processed $\mathrm{ZrO}_{2}$ ceramic coating. Thomazin et al. [34] employed finite element (FE) techniques to successfully model the laser spot welding of $\mathrm{Al}_{2} \mathrm{O}_{3}$.

\section{Thermal events associated with laser surface treatment of ceramic materials}

An understanding of the physical phenomena which occur during the HPDL surface treatment of the selected architectural materials is highly relevant for the modelling of the process. Interaction of the HPDL beam with the surface of the selected architectural materials is essentially a thermal process whereby material is removed by means of a phase change; either melting or vaporisation. In the case of the HPDL surface treatment of the selected architectural materials, the phase change is comprised of melting only. The temperature distribution in a semi-infinite workpiece during laser surface treatment can be described by the heat conduction equation [31]

$$
Q=\rho c_{p} \frac{\partial T}{\partial t}-\nabla \bullet(k \nabla T)+\nabla \bullet\left(U \rho c_{p} T\right)
$$

where $Q$ represents the heat source and heat sink in the workpiece, $T$ denotes the temperature at $(x, y$, $z, t$ ) relative to the ambient temperature, $T_{o}, t$ is time, $\rho$ is the density of the material, $c_{p}$ is the thermal capacity of the material and $k$ is the thermal conductivity of the material, $\mathrm{U}$ represents the fluid flow with respect to the co-ordinate system $(x, y, z)$ fixed to the laser beam.

There are basically three types of heat transfer involved in any laser processing operation: radiation; conduction and convection. The principal mode of heat transfer examined in the model is conduction. This is mainly for reasons of simplification, but also because in the HPDL surface treatment process, conduction appears to be the predominant heat transfer mechanism [35]. An established approach to solving the heat conduction equation (1), given its boundary and initial condition, is by the use of Green's functions [31]. Green's function, $G\left(x, y, z, t, x, y, z^{\prime}, t^{\prime}, v, k\right)$ represents the temperature at $(x, y, z)$ at time $t$, due to a point source of unit strength at $\left(x^{\prime}, y^{\prime}, z\right)$ at time $t^{\prime}$, which is moving with velocity $v$. So, by integrating the product of $G$ with the actual absorbed laser power density, $A(x, y$, $t$ ), over the dimensions of the laser spot and time, the temperature $T(x, y, z, t)$ induced by the laser beam moving over a surface $\left(z^{\prime}=0\right)$ is obtained by 


$$
T(x, y, z, t)=T_{0}+\int_{0}^{t} \int_{-\infty}^{\infty} \int_{-\infty}^{\infty} G\left(x, y, z, t, x^{\prime}, y^{\prime}, 0, t^{\prime}, v\right) A\left(x^{\prime}, y^{\prime}, t^{\prime}\right) d x^{\prime} d y^{\prime} d t^{\prime}
$$

Li et al. [36] has defined Green's function as a product of a steady state term, $W$, and a time dependent term, $U$, thus:

$$
G\left(x, y, z, t, x^{\prime}, y^{\prime}, 0, t^{\prime}, v\right)=W\left(x, y, z, x^{\prime}, y^{\prime}, v\right) U\left(x, y, z, t, x^{\prime}, y^{\prime}, t^{\prime}, v\right)
$$

\section{Theoretical meltpool geometry model}

The meltpool depth during HPDL surface treatment of the selected architectural materials determines the thickness of the resulting surface layer after solidification (i.e. the glaze thickness). Therefore, it is important to know the relationship between the geometry (depth) of the meltpool and the operating parameters, such as laser power and traverse speed. A simple analytical model can be obtained by assuming that the shape of the solid-liquid interface is parabolic for a circular beam spot and if the heat transfer is considered as one-dimensional as shown schematically in Fig. 1. These are reasonable assumptions according to Römer, who made similar assumptions when considering the laser surface treatment of titanium nitride [37].

The energy balance within the sample shown in Fig. 1 consists of three terms: the absorbed laser energy, $Q_{L}$, the energy transported by heat conduction from the liquid-solid interface of the meltpool into the non-molten material, $Q_{C}$, and the energy required to create a meltpool, $Q_{F}$ (assuming radiation energy loss is negligible). It is also assumed that the heat transfer under the meltpool may be considered as one-dimensional. Due to the relative velocity between the laser beam and the workpiece, energy is virtually removed from the interaction zone (convective losses). The energy, $Q_{F}$, required to create a meltpool is accounted for in the energy balance to compensate for these convective losses. In the case of the HPDL surface treatment of the selected architectural materials, only a small flow of $31 \mathrm{~min}^{-1}$ of gas is necessary in order to protect the optics, this effectively equates to a negligible gas flow. This being the case, the heat balance equation is:

$$
Q_{L}=Q_{C}+Q_{F}
$$

The laser energy, $Q_{L}$, absorbed by the workpiece, can be approximated by 


$$
Q_{L}=A P_{L} t_{i}
$$

where $t_{i}$ is the interaction time of the laser beam with a given point on the surface of the workpiece. The interaction time at the centre line of the meltpool along the direction of the beam traverse is

$$
t_{i}=\frac{d}{v}
$$

where $d$ is the diameter of the laser beam and $v$ the traverse speed. The energy, $Q_{C}$, which flows from the meltpool into the solid material can be calculated from the heat enclosed by the heat affected volume under consideration [37].

$$
Q_{C}=\rho c_{p} \int_{V_{s}} T\left(x, y, z, t_{i}\right) d V_{s}
$$

here $V_{s}$ is the volume of the heat affected zone (HAZ) in the solid under the meltpool and $T\left(x, y, z, t_{i}\right)$ denotes the corresponding temperature field at time $t=t_{i}$. It is assumed that the heat transfer under the meltpool may be considered as one-dimensional (e.g. z-axis). Thus the temperature, $T\left(x, y, z, t_{i}\right)$, is equal to the solution of the problem in which a semi-infinite sample attains a surface temperature equal to the melting temperature, $T_{m}$, at time $t=0[39]$ :

$$
T\left(z, t_{i}\right)=\left(T_{m}-T_{0}\right) \operatorname{erfc}\left(\frac{z}{2 \sqrt{\alpha t_{i}}}\right)+T_{0}
$$

The thickness of the heat-affected volume, $V_{s}$, is assumed to be equal to the heat penetration depth and $\alpha=k / \rho c_{p}$ is the thermal diffusivity of the material. The integral (7) can be evaluated if the area, $S_{s l}$, of the solid-liquid interface is known. The parabolic shape of the solid-liquid interface is described by the function

$$
z=z_{c}\left(\frac{x^{2}+y^{2}}{R_{m}^{2}}-1\right) \text { for } x^{2}+y^{2} \leq R_{m}^{2}
$$

where $z_{c}$ is the depth of the meltpool and $R_{m}$ is the radius of the meltpool. The area, $S_{s l}$, of the solidliquid interface is calculated from Equation (9) and is equal to 


$$
S_{s l}=2 \pi \int_{0}^{R_{m}} r \sqrt{1+\left(\frac{d z}{d r}\right)^{2} d r}
$$

Thus

$$
S_{s l}=2 \pi \int_{0}^{R_{m}} r\left(1+4 \frac{z_{c}^{2} r^{2}}{R_{m}^{4}} d r\right)^{1 / 2}=\frac{\pi R_{m}^{2}}{6 z_{c}^{2}}\left[\left(\frac{R_{m}^{2}+4 z_{c}^{2}}{R_{m}^{2}}\right)^{3 / 2}-1\right] \approx \frac{4}{3} \pi R_{m} z_{c}
$$

where $x^{2}+y^{2}=r^{2}$ has been used. Then, substitution of (6), (8) and (10a) into Equation (7) yields

$$
Q_{C}=\frac{4}{3} z_{c} \pi R_{m} \rho c_{p}\left(T_{m}-T_{0}\right) \int_{0}^{2 \sqrt{k d / v}}\left[\operatorname{erfc}\left(\frac{z v}{2 \sqrt{k d v}}\right)+T_{0}\right] d z
$$

The energy, $Q_{F}$, required to create a meltpool follows from the latent heat of fusion, $L_{f}$, per unit of the material, material density and the volume, $V_{l}$, of the meltpool [37]:

$$
Q_{F}=L_{f} \rho V_{l}
$$

in which $V_{l}$ can be calculated from (9):

$$
V_{l}=\int_{-z_{c}}^{0} \pi r^{2} d z=\int_{-z_{c}}^{0} \pi R_{m}^{2}\left(\frac{z}{z_{c}}+1\right) d z=\frac{\pi z_{c} R_{m}^{2}}{2}
$$

Substitution of Equation (13) into (12) yields

$$
Q_{F}=\frac{\pi L_{f} \rho z_{c} R_{m}^{2}}{2}
$$

Substitution of Equations (5), (6), (11) and (14) into the energy balance equation (4) and solving this equation for meltpool depth, $z_{c}$, yields

$$
z_{c}=\frac{A P_{L} d}{c_{p} \sqrt{d k v} R_{m} \rho\left(C_{1} T_{0}+C_{2} T_{m}\right)+\frac{1}{2} \rho R_{m}^{2} v \pi L_{f}}
$$

with the constants 


$$
\begin{aligned}
& C_{1}=\frac{8}{3}\left[\pi \operatorname{erf}(1)+\left(e^{-1}-1\right) \sqrt{\pi}\right] \approx 4.07 \\
& C_{2}=\frac{8}{3} \beta \pi-C_{1} \approx 4.31
\end{aligned}
$$

The model (15) can be significantly simplified by applying the following considerations:

- The initial workpiece temperature $T_{0}$ may be neglected compared to the melting temperature $T_{m}$ (e.g. $\left.T_{m}>>T_{0}\right)$.

- The latent heat of fusion is small compared to the total energy required for processing [39] (e.g. $Q_{F}<<Q_{L}$ ).

- Assuming the meltpool diameter equal to the laser beam diameter (e.g. $d=2 R_{m}$ )

Therefore,

$$
z_{c}=\frac{2 A}{\rho c_{p} C_{2} T_{m} \sqrt{k}} \frac{P_{L}}{\sqrt{d v}}
$$

This expression shows a linear dependence of the meltpool depth with the ratio $P_{L} / \sqrt{d v}$, which is sometimes referred to as the specific energy [40]. The same dependence was derived by Römer [37] and proved by experimental analysis by Derouet [41] in the case of laser transformation hardening for metals. Since ceramic materials such as those considered in this study are composed of at least two elements, often more, their crystal structures are generally more complex than those of metals and therefore the meltpool depth was corrected by a factor $\left(C_{3}\right)$. This factor was empirically deduced $\left(C_{3}\right.$ $=2.29)$ on the basis of many experimental results obtained for the selected architectural materials. Thus

$$
z_{c}=\frac{1}{C_{3}} \frac{2 A}{\rho c_{p} C_{2} T_{m} \sqrt{k}} \frac{P_{L}}{\sqrt{d v}}
$$




\section{Theoretical meltpool geometry model results and validation}

\subsection{Experimentally determined results}

\subsubsection{Experimental procedures}

The laser used in the study was a surgical HPDL (Diomed, Inc.), emitting at $810 \pm 20 \mathrm{~nm}$ and operating in the continuous wave $(\mathrm{CW})$ mode with rated optical powers ranging from $0-120 \mathrm{~W}$. The HPDL beam was delivered to the work area by means of a $4 \mathrm{~m}$ long, $600 \mu \mathrm{m}$ core diameter optical fibre, the end of which was connected to a 2:1 focusing lens assembly mounted on the z-axis of a 3axis $\mathrm{CNC}$ gantry table. The selected architectural materials were irradiated using the defocused high order mode HPDL beam with a beam spot diameter of $1.9 \mathrm{~mm}$ and laser powers (measured at the workpiece using a Power Wizard power meter) of 20-100 W. The defocused HPDL beam was fired across the surfaces of the selected architectural materials using the $\mathrm{x}$ - and $\mathrm{y}$-axis of the CNC gantry table at speeds ranging from $60-600 \mathrm{~mm} \mathrm{~min}^{-1}$. The laser optics were protected by means of a coaxially blown $\mathrm{O}_{2}$ shield gas jet a rate of $31 \mathrm{~min}^{-1}$.

The selected architectural materials were clay quarry tiles, ceramic tiles and OPC. For the purpose of experimental convenience the as-received OPC blocks were sectioned into squares $(120 \times 120 \times 20$ $\left.\mathrm{mm}^{3}\right)$ prior to HPDL treatment. The clay quarry and ceramic tiles were UK standard sizes $(120 \times 120$ $\left.\mathrm{x} 5 \mathrm{~mm}^{3}\right)$.

\subsubsection{Results}

A series of lines were marked onto the surface of the tile samples using output power of $17-51 \mathrm{~W}$ at rates of $120-480 \mathrm{~mm} \mathrm{~min}^{-1}$. These values of laser power were chosen after preliminary experiments that revealed laser powers below $17 \mathrm{~W}$ did not effect surface melting, whilst laser powers in excess of $51 \mathrm{~W}$ resulted in vaporization of the surface. Image processing software (Visilog 5) was used to measure accurately the depth and width of the mark. as indicated in Fig. 2. Table 1 details the melt depths observed in the selected architectural materials after HPDL surface treatment, $z_{m}$, along with the melt depths calculated using Equation (17), $z_{c}$.

\subsection{Comparison of the measured and calculated melt depths}

A comparison of the measured and calculated meltpool depths for the HPDL surface treatment of the selected architectural materials is presented in Fig. 3, which shows the melt depths as a function of 
the HPDL line energy, $P_{L} / \sqrt{d v}$. It is important to note that the melt depths are given in terms of HPDL line energy because the model used is one-dimentioanl in nature and does not, therefore, consider the area of the beam. For clarity and convenience the graph displays only the extreme values of the laser power, that is $17 \mathrm{~W}$ and $51 \mathrm{~W}$.

\section{Discussion}

From Fig. 3 the linear dependence of the melt pool depth with the HPDL line energy is clearly evident. The errors between the predicted and measured depth can be seen to increase with increasing laser power and decreasing time. The measured and calculated melt depth values are in closer agreement for values of HPDL line energy $<15 \mathrm{~W} \mathrm{~mm}^{-1} \mathrm{~s}^{-1 / 2}$. Beyond this value the measured and the predicted melt depths begin to diverge at an increasing rate. The poor correspondence at high values of HPDL line energy can be attributed to the shape of the melt pool, which, contrary to the assumption of the model of a parabolic shaped meltpool, is in fact not parabolic in shape at operating parameters beyond this limit. Consequently, the non-parabolic shape produced by increasing the laser line energy causes the model to calculate temperatures. This is mainly due to the fact that the model is one-dimensional and therefore intrinsically neglects sideways conduction, assuming all the heat transfer is by conduction downwards (in z-direction). In reality, the heat conduction flows in all directions. So, in instances wherein slow traverse speed and high laser power are employed (e.g. HPDL line energy $>15 \mathrm{~W} \mathrm{~mm}^{-1} \mathrm{~s}^{-1 / 2}$ ), the sideways conduction of energy, which is naturally significant under these conditions, is neglected, thus the errors between the predicted and measured melt depths are increased. Furthermore, it is believed that at depths which are smaller compared to the spot size (1.9 $\mathrm{mm}$ in this case), the heat transfer is approximately in one dimension only [41]. As such, the melt depths predicted by the model when the laser operating parameters are such that relatively shallow melt depths result, that is when the HPDL line energy is small, will be reasonably accurate. Whereas on the hand, when the laser operating parameters are such that relatively deep melt depths result, that is when the HPDL line energy is large, then the assumption of one-dimensional heat transfer no longer holds true and the predicted melt depths will be accordingly inaccurate. This assertion is borne out somewhat by comparing the measured and calculated melt depths from Table 1 and Fig. 3. 
The inhomogeneous nature of the selected architectural materials is also a considerable source of errors in the melt depths predicted by the model. Crystal structures for the minerals comprising the materials are complicated owing to the large numbers of components. Laser-induced heating changes the optical properties of materials via their temperature dependence. The change in absorbed laser light intensity, in turn, changes the temperature distribution. This feedback is strong enough, to cause new phenomena in the laser-matter interaction (e.g. thermal runaway, oscillation or multistabilities. Indeed, Bäuerle [42] has found that in composite materials and multilayer structured materials, the continuous and discontinuous changes in thermophysical and optical properties of the materials significantly changes the laser-induced temperature distribution with respect to those estimated for plane uniform (homogenous) substrates. As a result of this, the reflectivity and absorptivity of the laser beam by the material, becomes a multiple dimension complex function [42].

A matter of great interest is the apparent applicability of the correction factor, $C_{3}$, for all of the architectural materials selected for this study. It is believed that $C_{3}$ was appropriate because the compositions of the architectural materials chosen are all similar. In particular, the compounds that are primarily responsible for the formation of the surface glazes resulting from HPDL interaction, namely the glass network formers, $\mathrm{SiO}_{2}(30-50 \mathrm{wt} \%)$ and $\mathrm{Al}_{2} \mathrm{O}_{3}(5-15 \mathrm{wt} \%)$ and the glass network modifiers $\mathrm{Fe}_{2} \mathrm{O}_{3}(1-3 \mathrm{wt} \%)$.

\section{Conclusions}

A one-dimensional analytical model based on Fourier's law, with quasi-stationary situations in an isotropic and inhomogeneous workpiece with a parabolic meltpool geometry being assumed, was successfully developed. This model, with the inclusion of an empirically determined correction factor, predicted high power diode laser (HPDL) induced melt depths in clay quarry tiles, ceramic tiles and ordinary Portland cement (OPC) that were in close agreement with those obtained experimentally. It was observed, however, that as the incident laser line energy increased $(>15 \mathrm{~W}$ $\mathrm{mm}^{-1} \mathrm{~s}^{-1 / 2}$ ), the calculated and the experimental melt depths began to diverge at an increasing rate. It is believed that this observed increasing discrepancy is due to the fact the model neglects sideways conduction which, although it can be reasonably neglected at low energy densities, becomes significant at higher energy densities since one-dimensional heat transfer no longer holds true. 


\section{References}

1. Sugita K, Mori M, Fujioka T. Concrete Eng. 1986;24:3-22.

2. Hamasaki M. Proceedings of the International Symposium on Laser Processing, 1987, San Jose, CA., vol 852, p.68.

3. Yoshizawa H, Wignarajah S, Saito H. J. Japan Welding Soc. 1989;20:31-6.

4. Li L, Modern PJ, Steen WM. Proceedings of LAMP '92: Science and Applications, 1992, Nagaoka, Japan, pp. 843-8.

5. Li L, Steen WM, Modern PJ. Proceedings of ISLOE '93, 1994, Singapore, pp. 25-30.

6. Li L, Steen WM, Modern PJ, Spencer JT. Proceedings of RECOD '94, 1994, London, UK, pp. 24-8.

7. Li L, Steen WM, Modern PJ, Spencer JT. Proceedings of SPIE: Laser Materials Processing and Machining, 1994, Frankfurt, Germany, vol 2246, pp. 84-95.

8. Johnston EP, Shannon G, Steen WM, Jones DR, Spencer JT. Proceedings of ICALEO '98: Laser Materials Processing, 1998, Orlando, FL., vol 85, pp. 210-8.

9. Sugimoto K, Wignarajah S, Nagasi K, Yasu S. Proceedings of ICALEO '90: Laser Materials Processing, 1990, Boston, MA., vol 71, pp. 302-12.

10. Wignarajah S, Sugimoto K, Nagai K. Proceedings of ICALEO '92: Laser Materials Processing, 1992, Orlando, FL., vol 75, pp. 383-93.

11. Borodina TI, Valyano GE, Ibragimov NI, Pakhomov EP, Romanov AI, Smirnova LG, Khabibulaev PK. J. Phys. Chem. Mater. Treatment 1991;25:541-6.

12. Lawrence J, Li L. Proceedings of ICALEO '99: Laser Materials Processing, 1999, San Diego, CA., vol 87, pp. 108-17.

13. Lawrence J, Li L. Mater. Sci. Eng. A 2000;284:93-102.

14. Lawrence J, Li L. Mater. Sci. Eng. A 2000;287:25-2.

15. Lawrence J, Li L. J. Laser Apps. 2000;12:72-84.

16. Livingstone SAJ, Black I. Lasers in Eng. 1996;5:127-38.

17. Livingstone SAJ, Chua KL, Black I. J. Laser Apps. 1997;9:233-41.

18. Black I, Livingstone SAJ, Chua KL. J. Mater. Proc. Tech. 1998;84:47-55. 
19. Black I, Chua KL. Optics Laser Tech. 1994;24:193-205.

20. Chua KL, Black I. Lasers in Eng. 1998;6:291-314.

21. Solomah AG. Proceedings of the International Conference on Machining of Advanced Materials, 1993, Gaitersburg, MD., vol 847, pp. 543-6.

22. Markov EM, Voronezhtsev YI, Goldade VA. Glass and Ceramics 1990;47:83-8.

23. Kugler TR, Culkin TJ. Hybrid Circuit Tech. 1989;6:45-8.

24. Smith RN, Surprenant RT, Kaminshki DA. J. Laser Apps. 1992;4:25-32.

25. Li K, Sheng P. Int. J. Mach. Tools Manuf. 1995;35:1493-1506.

26. Marvo H, Miyamoto I, Ooie T. Quarterly J. Japan Welding Soc. 1992;10:123-8.

27. Ogata K, Miyanagi N, Suzuki K, Shimoura Y. Proceedings of ICALEO '90: Laser Materials Processing, 1990, Boston, MA., vol 71, pp. 261-5.

28. Shigematsu I, Kanayama K, Hira Y, Nakamura M. J. Ceramic Soc. Japan 1993;101:591-3.

29. Jeager JC. Proc. Royal Soc. N.S.W. 1942;76:203-24.

30. Rosenthal D. Trans. ASME 1946;68:849-66.

31. Carslaw HS, Jaeger JC. Conduction of heat in solids. London: Oxford University Press, 1959.

32. Patankar SV. Numerical heat transfer and fluid flow. New York: Hemisphere Publishing, 1980.

33. Cheng J, Kar A. J. Mater. Sci. 1997;32:6269-78.

34. Thomazin JA, Olson LG, Hirsch JW. Int. J. Num. Meth. Heat Fluid Flow 1996;6:35-46.

35. Lawrence J. PhD Thesis, University of Manchester Institute of Science \& Technology (UMIST), 1999.

36. Li J, Chen QH, Merlin J, Fan Z. Chinese J. Lasers 1997;B6-3:280-8.

37. Römer GRBE. PhD Thesis, The University of Eiberger, 1995.

38. Kuilboer RB, Kirner PK, Meijer J, Rund M, Schneider MF. Annals of CIRP 1994:43:585-92.

39. Easterling KE. Introduction to the physical metallurgy of welding. Oxford: ButterworthHeinemann, 1992.

40. Schneider MF. PhD Thesis, The University of Twente, 1995.

41. Harada K, Toshio T. Fire Safety Sci. 1989;1223:707-17.

42. Bäuerle D. Laser processing and chemistry. Berlin: Springer Verlag, 1996. 


\section{List of Figs.}

Fig. 1. Meltpool geometry and energy flows in a quasi-stationary situation.

Fig. 2. Cross-sectional optical micrograph showing the parabolic shape of the glaze for clay tile. Note the HAZ, depth and width of the glaze.

Fig. 3. Measured and calculated melt pool depth for clay quarry tiles. 
Fig. 1

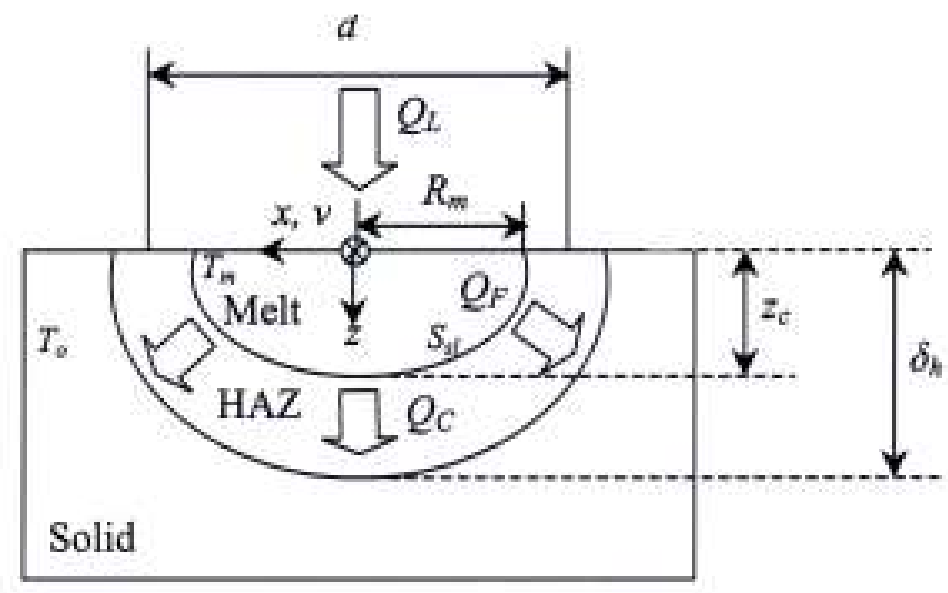


Fig. 2

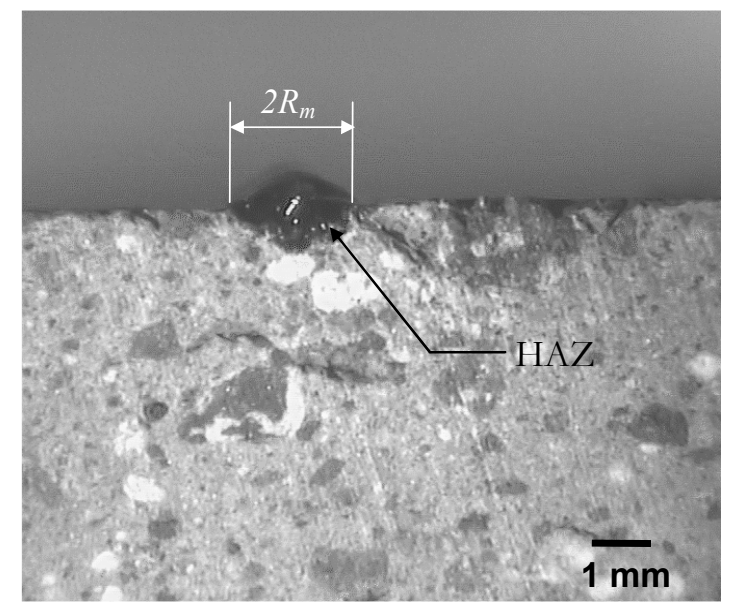


Fig. 3

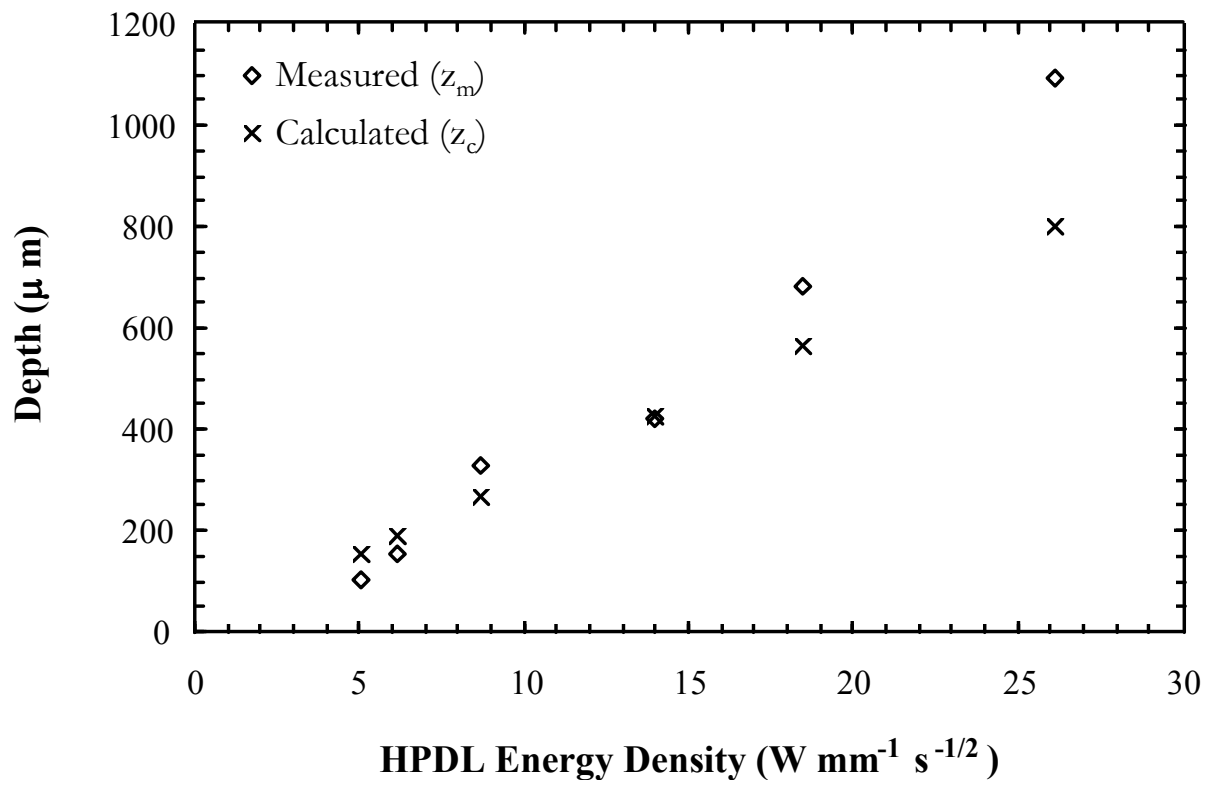




\section{List of Tables}

Table 1. Measured $\left(\mathrm{z}_{\mathrm{m}}\right)$ and calculated $\left(\mathrm{z}_{\mathrm{c}}\right)$ HPDL induced melt depths on the selected architectural materials. 
Table 1

\begin{tabular}{|c|c|c|c|c|c|c|c|}
\hline \multirow{3}{*}{$\begin{array}{c}\text { Laser Power, } \\
\text { P }_{\mathrm{L}}(\mathrm{W})\end{array}$} & \multirow{3}{*}{$\begin{array}{c}\text { Traverse Speed, } v \\
(\mu \mathrm{m})\end{array}$} & \multicolumn{6}{|c|}{ Selected Architectural Materials } \\
\hline & & \multicolumn{2}{|c|}{ Clay Quarry Tile } & \multicolumn{2}{|c|}{ Ceramic Tile } & \multicolumn{2}{|c|}{ OPC } \\
\hline & & $\mathbf{z}_{\mathrm{m}}(\mu \mathbf{m})$ & $\mathbf{z}_{\mathrm{c}}(\mu \mathrm{m})$ & $\mathbf{z}_{m}(\mu \mathrm{m})$ & $\mathrm{z}_{\mathrm{c}}(\mu \mathrm{m})$ & $\mathbf{z}_{m}(\mu \mathrm{m})$ & $\mathrm{z}_{\mathrm{c}}(\mu \mathrm{m})$ \\
\hline \multirow[t]{3}{*}{17} & 6 & 104 & 154 & 91 & 135 & 117 & 173 \\
\hline & 4 & 156 & 188 & 139 & 169 & 161 & 194 \\
\hline & 2 & 330 & 266 & 302 & 240 & 335 & 270 \\
\hline \multirow[t]{3}{*}{25} & 6 & 187 & 231 & 181 & 224 & 191 & 238 \\
\hline & 4 & 280 & 283 & 276 & 281 & 285 & 290 \\
\hline & 2 & 530 & 400 & 527 & 398 & 542 & 407 \\
\hline \multirow[t]{3}{*}{34} & 7 & 234 & 214 & 232 & 210 & 239 & 219 \\
\hline & 5 & 307 & 253 & 297 & 243 & 315 & 261 \\
\hline & 3 & 610 & 326 & 602 & 318 & 621 & 333 \\
\hline \multirow{3}{*}{43} & 6 & 366 & 385 & 359 & 378 & 370 & 389 \\
\hline & 4 & 530 & 471 & 529 & 409 & 536 & 482 \\
\hline & 2 & 960 & 666 & 954 & 667 & 964 & 671 \\
\hline \multirow[t]{3}{*}{51} & 7 & 420 & 427 & 417 & 425 & 425 & 432 \\
\hline & 4 & 680 & 565 & 677 & 563 & 688 & 575 \\
\hline & 2 & 1090 & 799 & 1083 & 794 & 1094 & 802 \\
\hline
\end{tabular}

